\title{
AMÉRICA EN LOS ATLAS DE HUMANISTAS HOLANDESES
}

Para los tiempos que corrían, Europa no tardó en enterarse de la existencia de América. La carta de Colón que anunciaba el descubrimiento a los Reyes de España, fechada el 14 de marzo de 1493, vio la luz, como se recordará, en múltiples ediciones. En ese mismo año, hubo doce: la original, en castellano, publicada en Barcelona, más ocho en latín y tres en italiano, lo que para aquel entonces no era corriente. Después aparecerían la alemana y la segunda en castellano, ambas en 1497. Todas estas ediciones se publicaron en ciudades cuyo prestigio cultural y posición geográfica aseguraban la pronta difusión del texto y su acogida en el circuito de los lectores cultos de la Europa de aquellos años: Roma, Amberes, Basilea, París, Florencia y Estrasburgo, y en la península: Barcelona y Valladolid ${ }^{1}$. Así comienza la historia impresa de las culturas y pueblos de América ${ }^{2}$ en el viejo continente.

Los europeos tenían que imaginarse todo aquello nuevo a través de la palabra impresa: gentes y vegetación, costas y volcanes, construcciones arquitectónicas y fauna. No es de extrañar que, en los primeros tiempos, la imaginación europea careciera de instrumentos conceptuales para representarse adecuadamente lo que los ojos no habían visto aún y que virtiera lo leído y lo oído en moldes familiares, europeos ${ }^{3}$. Hasta la forma de ese continente

1 Carlos Sanz (ed.), La Carta de Colón anunciando el Descubrimiento del Nuevo Mundo, 15 febrero-14 marzo 1493, Madrid, 1961. Para todos los datos bibliográficos referentes a libros sobre América, véase: John ALDEN (ed.), European Americana: A Chronological Guide to Works Printedin Europe Relating to the Americas, 1493 to 1750 , New York, $1980-1992,6$ ts.

2 En lo que sigue, emplearemos el nombre de América para la parte descubierta por españoles y portugueses.

3 Véase Jean-Paul Duvlols, L'Amérique vue et rêvée. Les récits de voyage de Christophe Colomb à Bougainville, Paris, 1985, passim.

NRFH, XL (1992), núm. 1, 85-98 
desconocido (y el curso de sus ríos, la localización y formas de sus sierras y cordilleras) era materia de especulación durante los primeros decenios del siglo xvI para los que no habían pasado a ultramar. Bien es verdad que ya en 1500 Juan de la Cosa había confeccionado un mapa en que quedaba consignado todo lo que entonces se sabía de la geografía de ciertas partes de América - las islas y ciertos sectores de la costa-, pero ese mapa no fue editado, por lo cual la información, generalmente bastante correcta, que contenía quedó inaccesible a los que podían interesarse por tales cuestiones.

En lo que sigue quisiéramos ofrecer algunos datos sobre lo que acerca de la geografía de América estaba al alcance de los intelectuales de una parte de Europa que tradicionalmente mantenía contactos comerciales (marítimos, fluviales y terrestres) e intelectuales con Inglaterra, Francia, los principados alemanes y con España y Portugal: los Países Bajos. Nos ocuparemos principalmente de los Países Bajos Septentrionales, puesto que de allí procede el material de nuestro trabajo: un número de catálogos (impresos) de venta en pública subasta de bibliotecas de intelectuales, para los que emplearemos el término "humanistas holandeses" 4 . Lo de "humanistas", por tratarse sin excepción de hombres cuyas bibliotecas ostentaban una impresionante y preponderante presencia de los clásicos; "holandeses", para evitar una terminología pesada ("de los Países Bajos Septentrionales"). Conviene tener en cuenta que, contrariamente a lo que pasaba en el resto de Europa, el Humanismo de los Países Bajos se sitúa entre los años 1500 y 1700 . Y también, que la aportación cultural de los que se trasladaron a los Países Bajos Septentrionales, sobre todo después de la caída de Amberes en 1585 como resultado de la campaña militar de Farnesio, ha sido importante en más de un terreno. Fue también a partir de 1585 cuando Amsterdam se fue convirtiendo en el emporio que hasta entonces había sido Amberes y cuando la producción de libros y mapas se fue haciendo principalmente en el norte.

4 Se trata de 139 catálogos de ventas realizadas por su mayor parte en Leiden entre 1599 y 1700. En junio de 1991 leímos una ponencia titulada "Dutch Humanists' Knowledge of America'" en la International Conference on the Intellectual Consequences of the Discovery of the New World, "America in European Consciousness, 1493-1750", organizada por The John Carter Brown Library, Providence, RI; en ella se ofrecían los resultados del despojo de 114 catálogos para comprobar la presencia de libros sobre América en bibliotecas holandesas de los siglos XVI y XVII. 
Antes de ocuparnos de la cosmografía de Sebastián Münster (1544) y de ciertos atlas en los que aparece América, es conveniente detenerse un momento en algunas ediciones de libros que traían mapas del Nuevo Mundo. El carácter de estos mapas oscila entre unos dibujos toscos o fantásticos, por un lado, y representaciones geográficas ya más correctas y completas, por otro ${ }^{5}$. Nos fijaremos sólo en los títulos que hemos encontrado en nuestros catálogos. Como éstos no siempre dan el pie de imprenta completo, o sólo mencionan un título difícil de identificar, incluso con la ayuda de la gran bibliografía descriptiva contenida en European Americana, nuestros apuntes sólo tienen un carácter global.

Lo que parece ser la primera representación geográfica de una parte de América ("Santo Domingo en la Isla Isabela"), por lo demás fantástica, figura en El libro del famoso Marco Polo veneciano de las costas maravillosas que vido en las partes orientales (Sevilla, 1503). Sin embargo, el primer libro que contiene un mapa del nuevo continente, que hemos encontrado en nuestros catálogos, es $P_{1}$ Martyris Anglerii mediolanensis opera. Legatio Babylonica. Oceani Decas. Poemata. Epigrammata (Sevilla, 1511). En esta edición, las islas vienen trazadas de una forma muy tosca y vaga, así como parte de la costa de Venezuela. De los 14 ejemplares de Pedro Mártir que vienen mencionados en nuestros catálogos, sólo uno permite decir a ciencia cierta que se trata de esta edición sevillana. Cronológicamente, le sigue la Segunda Carta de Cortés, que en varias ediciones (Sevilla, 1522; a $^{\mathrm{a}}$ ed.: Zaragoza y Amberes; traducción al latín: Nuremberga, 1524, y traducción italiana: Venecia, 1524) iba acompañada de un mapa de Tenochtitlan ${ }^{6}$, que, por deficiente que sea, ofrecía una primera vista de aquella Venecia nueva que había impresionado tanto a los primeros europeos que la contemplaron. De este texto hemos encontrado muy pocos ejemplares (tres); es probable que formara parte de varias obras "antológicas" sobre los descubrimientos, que se hicieron en varias lenguas. Un ejemplo es el Novus Orbis diversorum auctorum, cum aliis aliquot consimilis argumenti libellis, que se publicó en Basilea en 1532 y que contenía un mapa. Estas colecciones antológicas son las peor

5 Véanse: Francisco Vindel, Mapas de América en los libros españoles de los siglos xvi al xviii (1503-1798), Madrid, 1955-1959, 2 ts.; para mapas de América: America in Maps. Dating from 1500 to 1856, comp. and ed. by Egon Klemp, New York-London, 1976; para la cartografía en general: NumA BROC, La géographie de la Renaissance, Paris, 1986.

${ }^{6}$ Cf. Hernán Cortés. Letters from Mexico, trans. and ed. by A. R. Pagden, with an Introduction by J. H. Elliott, 1972, pp. lx-lxi. 
descritas, bibliográficamente. El Arte de navegar de Pedro de Medina (Valladolid, 1545) tuvo mucho éxito y fue traducido al francés, italiano, inglés y holandés (1580). La primera edición del libro, así como la mayor parte de las siguientes y las traducciones, contenían la "Carta de navegar al Nuevo Mundo" que su autor había confeccionado. Como todavía estamos trabajando en este tema, no podemos ofrecer aquí datos seguros. De todas formas, en el mapa de Medina figuran, aunque todavía sin gran exactitud, Centroamérica y América del Sur, aparte de la costa meridional de los actuales Estados Unidos (que figura en la mayor parte de los mapas en que vienen representadas las islas del Caribe e Hispania Nova). En la edición del mismo libro hecha en Sevilla en 1549, el mapa resulta más correcto —las islas ya están "en su sitio" - y lo mismo cabe afirmar de la edición sevillana de 1563. La Historia de las Indias y Conquista de México de Gómara (Zaragoza, 1552) traía un mapa de "Toda la tierra de las Indias" y la Parte Primera de la Chrónica del Perú (Sevilla, 1553) de Cieza de León contenía un mapa del "Cerro del Potosí". Es, sin embargo, en la edición de su Crónica del Perú, hecha en Amberes en 1554, donde figura por vez primera un mapa del Nuevo Mundo detallado, bastante correcto en cuanto a la forma del continente y en el que se dedica mucha atención a la toponimia (la mayor parte de los nombres de lugar se encuentra, evidentemente, a lo largo de las costas). En el siglo XVI, de todas las ediciones de Gómara, en castellano y en traducción a otras lenguas, sólo las de Medina del Campo y Zaragoza, ambas de 1553, y una de las tres que se hicieron en Amberes (la que se hizo en la casa de Bellère) llevaban mapa. De los 15 ejemplares que hemos encontrado de Gómara, no hay ninguna edición de 1553 y los editados en 1554 no especifican editor. En cuanto a Cieza de León, sólo una de las ediciones antverpienses (también hecha en la casa de Bellère) lleva mapa; los ocho ejemplares que hemos encontrado, de los cuales hay dos descritos como procedentes de Amberes, 1554, sin más datos, tampoco permiten llegar a una conclusión segura. La voluntad de descripción completa de la historia de América que se hace patente en la Historia general de los hechos de los castellanos en las islas y tierra firme del Mar Océano (Madrid, 1601-1615, 4 ts.) de Antonio de Herrera, se refleja en el panorama geográfico "completo" que pretende ofrecer en una serie de 14 mapas. En el primero de ellos, vienen representadas Centroamérica y América del Sur. Los otros van dedicados a: 2) "las Indias del Norte", 3) "la Audiencia de la Española", 4) las de la "Nueva España", 5) "Nueva 
Galicia" y 6) "Guatemala". Siguen los mapas de: 7) "las Indias del Mediodía" (la punta meridional de Centroamérica y toda la América del Sur), 8) las Audiencias de Panamá, 9) "del Nuevo Reino" (desde el Golfo de Urabá hasta el Lago de Maracaibo), 10) de "Quito", 11) de "Lima" y 12) "de las Charcas". Terminan la serie los de la "Provincia de Chile" y de "las Indias del Poniente" (las Filipinas). La toponomia es muy escasa en el primer mapa general y nula y escasísima, respectivamente, en los mapas generales 2 y 7; escasa también en los de Nueva España y Nueva Galicia. Con más abundancia aparecen los nombres de lugar en los mapas de Guatemala, Panamá, Lima, Charcas y Chile y realmente abundan en los que van dedicados a la Audiencia de la Española, el Nuevo Reino y Quito. Llama la atención la cantidad de topónimos del interior en los mapas del Nuevo Reino y Quito, sobre todo si se compara con la relativa escasez de los mismos en el territorio mejor conocido y desde hacía más tiempo, Nueva España. Como quiera que ello sea, los mapas de la Historia de Herrera dieron a los lectores de entonces una idea muy completa de la geografía de América. Este libro figura once veces en los catálogos; en ocho casos se trata de las ediciones latina y holandesa hechas en Amsterdam en 1622, en las que figuraban los 14 mapas. Curiosamente, Ramusio, en la tercera parte (1556) de cuyo libro Delle navigazioni e viaggi, que tanto éxito tuvo en Europa, figura América, sólo consta dos veces en nuestros catálogos.

Considerado en sí, el número de libros en los que figuraban mapas de las Indias no es impresionante, pero hay que añadirlo al total de libros de historia de América y al de total de los atlas en que figuraba el continente.

En 1544 se publicó en Basilea un libro que iba a tener una difusión enorme hasta bien entrado el siglo xvII, como lo testimonian, entre otras cosas, sus 36 ediciones, de las cuales 33 se hicieron antes de $1600^{7}$. Se trata de la cosmografía universal que el hebraísta y cosmógrafo alemán Sebastián Münster (1489-1552)

7 Hemos usado: Sebastian Münster. Cosmographei (Basel 1550), with an Introduction by Prof. Dr. R. Oehme, Theatrum Orbis Terrarum, Amsterdam, 1968. Para los atlas de Mercator, Ortelius, Hondius, Blaeu y Janssonius, véase: Dr. Ir. C. Koeman, Atlantes Neerlandici, Amsterdam, 1967-1985, 6 ts. La Biblioteca de la Universidad de Leiden es particularmente rica en mapas y atlas antiguos; el conservador de la colección, Dirk de Vries, está preparando una bibliografía descriptiva de los fondos relacionados con América y es autor de una introducción, en holandés, a los mapas que describen la primera fase del descubrimiento de América. 
había escrito en su lengua materna y titulado Cosmographei. Es un verdadero calepino (tiene 1233 páginas), profusamente ilustrado con xilografías que representan usos y costumbres, flora y fauna, vistas de ciudades y puertos, barcos y utensilios, en fin, todo lo que por entonces se sabía del mundo entero. Sin embargo, aparte de algunas excepciones (vistas de ciudades alemanas principalmente), las estampas que se refieren a países situados fuera de Europa se basan en gran parte en la fantasía de los artistas, por más que se atengan a lo que se había dicho y escrito sobre aquéllos desde la Antigüedad clásica. Además, y como ocurre con cierta frecuencia, una misma estampa se utiliza más de una vez, en diferentes contextos, a lo largo del texto. Para su cosmografía, Münster usó todas las fuentes literarias grecolatinas y contemporáneas (parece haber desdeñado los textos medievales), tanto impresas como manuscritas, de las que pudo echar mano, y de mapas.

El libro se inicia con un mapamundi en que, de forma fantástica, figura "America vel Brasilij ins.", representada hasta el "Fretü Magallianum", y en el que se ven "Cuba", "Hispaniola" y “Terra Florida". Después de la descripción de África, viene un mapa que representa "Die nüw weldt oder Inseln so hinder Hispanien gegen Orient beij dem land India liegen'; Münster ya había hecho un mapa del Nuevo Mundo para la edición de Ptolomeo, Basilea, $1540^{8}$. En el lugar del actual nordeste brasileño, indicado como la región de los "Canibali", hay un dibujo de un bohío: cuatro palos floridos, dispuestos en forma cónica, de los que cuelgan una cabeza y una pierna humanas. En el norte $d \epsilon$ Venezuela se lee "Parias abundat auro \& margaritis", mientras que la región al sur del Río de la Plata viene marcada como "Re. gio Gigantum".

El Quinto Libro trata "Von den neüwen inseln wann und vor wem die erfunden wie sie heissen und für leüt darin seind" (todc un programa antropológico) y de "Die dritte schiffung so Colum. bus zu den neüwen inseln hat gethan'. En las nueve páginas de. dicadas a esta parte del mundo, Münster se refiere al origen dt Colón, sus preparativos para el viaje y llegada a las Canarias, y se detiene casi exclusivamente en la descripción de las islas segúr lo que cuenta de ellas Colón, aprovechando también algunos da tos que proceden de Vespucio. De pasada menciona Paria y a final del texto figuran dos frases sobre "la isla Yucatana" y l: de Cozumel. Los lectores de entonces habrán quedado impresio

8 Numa Broc, op. cit., p. 79. 
nados por lo que dice el texto acerca del concierto que estaban dando los ruiseñores, cantando a todo pulmón, cuando Colón y sus hombres costeaban la isla Juana: lo primero que cuenta Münster acerca de América. Apenas cabe imaginar una introducción más poética al Nuevo Mundo. En lo que sigue, se refiere a que esos hombres y mujeres desnudos acogían muy bien a los españoles, les daban oro y se quejaban ante ellos de las incursiones caníbales (siguen algunos detalles sobre las costumbres de los antropófagos). Los demás datos que selecciona Münster de sus lecturas son: la mediana estatura de la gente, su color rojizo y el hecho de que no dejaban crecer ningún pelo en sus cuerpos; la ausencia de hierro y otros metales y la costumbre de los indígenas, gente muy aseada, ya que se lavaban con frecuencia, de dormir en redes de algodón que tendían "en el aire". Además, la poligamia y la aparente ausencia de un Dios que domine la vida. Por fin, la construcción de las casas - en forma de campana y cubiertas de hojas de palma - y el pan muy bueno que se hacía, no obstante la falta de trigo, de una variedad de raíces. Esto es lo que contiene, dicho de forma abreviada, el libro sobre América. Las estampas (hay dos dedicadas a las Islas Canarias: una, de la caña de azúcar; otra, del volcán Teide en plena erupción) representan: una ciudad (puramente europea, por supuesto), el bohío que ya hemos mencionado, pero esta vez sin trozos del cuerpo humano colgados, y dos escenas de las prácticas de los antropófagos. En la primera, un hombre y una mujer desnudos, colocados cada uno a un lado de una mesa alargada, grande, están cortando, cuchillo de carnicero en alto, un cuerpo humano. En la segunda, un hombre, algo soñador, vestido a la europea, está dando vueltas pacientemente a un asador en que se está tostando un cuerpo humano. Por lo demás, el bohío también figura en la parte dedicada a África; la estampa del asador aparece también en los apartados dedicados a África y Tartaria, y la carnicería vuelve a producirse en la descripción de las islas de Java y Borneo.

Aunque desde el punto de vista geográfico el libro no resulta muy interesante, tiene su importancia, ya que al lado de lo fantástico también contiene información procedente de Colón, Vespucio, Pedro Mártir y Oviedo (el Sumario). La popularidad de la que gozó viene corroborada por la frecuencia con que figura en las bibliotecas.

La realidad geográfica de América se fue desvelando poco a poco a los europeos a partir de los primeros mapas y atlas. En el mapa de Cantino (1502) aparece la costa del nordeste brasileño 
y las islas; el de Contarini (1506) da las islas y una masa tose del subcontmente, y el famoso mapamundi de Waldseemüller, $\mathrm{d}$ 1507, nos da ya alguna idea de los contornos de América. El pri mer atlas en que figura el continente es la edición de la Geographi de Ptolomeo por Waldseemüller en 1513. América aparecía ya d forma bastante correcta, y con muchos detalles, en el mapa d Diogo Ribeiro (ca. 1532), así como en el mapamundi del flamenc Gerardo Mercator (1512-1594), que apareció en 1538. Viene bas tante bien delineada en el de Paolo Forlani (1665), mientras qu el mapa de Diogo Homem, de 1568, representa el subcontinent como una masa tosca. Es con la "Nova et aucta Orbis Terrae Des criptio ad usum Navigantium emendatè accomodata" (1569) d Mercator que América entra en la cartografía internacional co: un nuevo tipo de proyección. El número de topónimos va aumen tando a partir del mapa de Forlani, que ya ostenta una cantida considerable. En este mapa de Mercator para uso de los nave gantes figura gran parte, bien representada, del nuevo continer te: desde Norteamérica hasta Cuzco; en cuanto a la América ibé rica, llama la atención el número de topónimos, principalment a lo largo de las costas, y de nombres de ríos. Encima de la part del mapa dedicada a "Hispania Nova" viene escrita, a la altur de la actual Baja California, la palabra "India'. En el Atlas - non bre que él introdujo, refiriéndose, como se lee en su prólogo, $\mathrm{n}$ a la conocida figura mitológica, sino a un sabio administrador d reino de Etruria-, la totalidad de América sólo figura en la ed: ción de 1606 preparada por Jodocus Hondius (1563-1612), quie en 1604 había comprado las planchas de cobre de este atlas d Mercator. En esta edición de 1606 figuran 37 mapas nuevos, prc cedentes de varios cartógrafos, entre los cuales hay seis de "Ami rica sive India Nova"; trae una "Hispaniae Novae Nova De: criptio" y en el mapa dedicado a la "America Meridionalis" $f$ gura un grabado de "Cusco metropolis Peru".

Un año después del mapa "ad usum navigantium" de $\mathrm{Mel}$ cator, se publicó en Amberes, en casa de Plantino, el Theatru: Orbis Terrarum del flamenco Abraham Ortelius (1527-1598). Es atlas de 1570 contenía 53 mapas de los mejores geógrafos de aqu llos tiempos. Se trata de mapas modernos que Ortelius había vi nido reuniendo durante años, de los que había uniformado el fo: mato, la escala y la proyección; en ciertos casos había mandad grabar nuevos mapas para mejorar la calidad de los existentes

${ }^{9}$ Ibid., p. 180. 
Los textos, escritos por el propio Ortelius, están todos en latín. Este atlas tuvo gran éxito: se hicieron numerosas ediciones, con el texto traducido al holandés, alemán, francés, italiano, inglés y español (esta última traducción apareció sucesivamente en 1588, 1602 y 1612), pero después de 1612 fue siendo eclipsado por los atlas de Hondius (que ampliaba el de Mercator) y, sobre todo, por los de Blaeu.

Ortelius cita 87 nombres de cosmógrafos y cartógrafos de cuyas obras ha tomado materiales prestados. La colección de mapas de este atlas se inicia con un mapamundi titulado "Typus Orbis Terrarum", al cual sigue "Americae sive Novi Orbis, Nova Descriptio". Sólo después vienen los mapas generales de Europa, Asia y África. En la página que precede al mapa general de América, Ortelius menciona sus fuentes, diciendo: "Hi sequentes ex professo de ea scripserunt: sed vernacula lingua omnes, quae utplurimum Hispanica est; sed Italica interpretati magna ex parte etiam extant'. Y siguen los nombres de : Cieza de León, Oviedo, Cortés, Pedro Alvarado, Diego Godoy, Cabeza de Vaca, Nuño de Guzmán, Francisco Ulloa, Francisco Vázquez, Antonio Mendoza, fray Marcos de Niza, Fernando [Ruiz] de Alarcón, Francisco Xerez, Verrazzano, Vespucio, Gómara, Benzoni, Cartier, Thevet y Von Staden - extenso e interesante elenco. Sobre todo si se tiene en cuenta que en un párrafo anterior se decía: "Quarum omnium Regionum cognitionem legere potest Geographiae studiosus apud Leuinum Apollonium; Petrum Martyrem Mediolanensem; Maximilianum Transsylvanum, qui Latina lingua de iis scripserunt. Plura non negligenda etiam videre sunt inter Iesuitarum epistolas. Promittit \& Postellus Commentaria rerum Atlanticarum". ¡Toda una bibliografía, casi exhaustiva para el período, para los que querían enterarse a fondo de la materia!

En el mapamundi, la forma de América resulta aún algo torpe: por otra parte, el mapa de América abunda en detalles topográficos y topónimos indígenas. En la edición de Amberes de 1579, el orden de presentación de los continentes ha vuelto a ser el tradicional: primero, Europa y luego Asia, África y, por fin, el Novus Orbis. Pero en esta edición hay una ampliación considerable: "Nova Hispania" viene representada detalladamente y acompañada de texto, así como "Peruvia"; además, hay mapas de "La Florida" y de "Guastecan Reg.", de "Culiacana Provincia" y de "Cuba et Spagniola". En la edición de 1592, también de Amberes, América figura ya de forma bastante correcta.

Para tener una idea aproximada de lo que costaba un atlas 
en aquellos años, y de quienes podían costearse la adquisión de tal tipo de libros, sirvan los datos siguientes. El de Europa de Ortelius, de 147 mapas, costaba 23 florines en 1598; un Mercator de 105 mapas, 19 florines. Alrededor de 1600, el salario anual de un obrero especializado era de 255 florines; el sueldo anual de los catedráticos de la Universidad de Leiden oscilaba, según una lista de pagos de 1593 que se conserva, entre los 400 y los 600 florines; en 1593, los bedeles ganaban 72 florines $^{10}$.

Hasta qué punto la geografía era considerada como una ciencia importante en la Europa de aquel entonces, se deduce del hecho de que en 1616 la Universidad de Leiden nombró a Felipe Cluverius (1580-1623) "Geographus Academicus"'11.

En 1635 se publicó en Amsterdam el Theatrum Orbis Terrarum sive Novus Atlas de Guillermo Blaeu (1571-1638), cartógrafo de los Países Bajos Septentrionales, fundador de la casa que llevaría su nombre y que florecería hasta fines del siglo xvII, para desaparecer en 1712. En este magnífico atlas, América ocupa su debidc lugar en el mapamundi con que se inicia la obra; el mapa corográfico del continente representa América ya prácticamente en la forma en que la conocemos y con una abundancia de detalles topográficos. A ambos lados de esta mapa figuran, enmarcándolo, cinco grabados que ostentan varios tipos de indígenas de Améri. ca. En la columna izquierda están representados, de arriba abajo, los: "Groenlandi", "Virginiani", los "Rex et regina Floridae", el "Novae Albionis Rex" y una pareja de "Mexicani". En la de la derecha podemos admirar los: "Peruviani", "Brasi. liani", unos "Brasiliani milites", algunos "Insulani de la Moche in Chili"' y los "Fretu Magallani accolae". Muestra representativa, se diría, de los habitantes del nuevo continente, por más que - aparte ciertos atavíos que distinguen a unos habitantes de otros - las imágenes resulten algo estereotipadas. Este atlas, cons. tantemente reeditado, no contiene mapas corográficos de Améri. ca ni texto descriptivo.

El hijo de Guillermo, Juan Blaeu (1596-1673), continuó la obré iniciada por su padre y produjo, entre 1648 y 1665 , su Atlas Maio:

10 B. VAN SELM, Een menighte treffelijcke boecken. Nederlandse boekhandelscata logi in het begin van de zeventiende eeuw [Cantidad de libros excelentes. Catálogo: de librerías neerlandesas de principios del siglo XVII], Utrecht, 1987, p. 302 n. 182 , y pp. $47-48$.

11 Véanse: Leiden University in the Seventeenth Century. An Exchange of Learn ing, ed. by Th. H. Lunsingh Scheurleer and G. H. M. Posthumus Meyjes Leiden, 1975, pp. 413-415, 448 y 454, y NumA BROC, op. cit., p. 198. 
en 11 tomos, obra cumbre de la cartografía europea, editada en tres ediciones diferentes: con texto latino, francés y español ${ }^{12}$. En la "octava parte"' del atlas figuran: España, África y América; esta última parte del mundo viene representada por un mapa general y 11 mapas corográficos, cuyos textos descriptivos cubren nada menos que 58 páginas (formato folio, como todos los atlas), verdadera enciclopedia de todo lo que se sabía en aquella época de América. Como Ortelius, un siglo antes, ya mencionó una extensa lista de cosmógrafos e historiadores de Indias de los que había tomado su información, no tiene mucho sentido tratar de averiguar de qué fuentes exactas procede la que ofrece esta edición del atlas de Blaeu, tanto más cuanto que vienen mencionadas con frecuencia ("Como dice Acosta...", "Cuenta Herrera que. . .", etc.). Estos textos descriptivos (de los que nos ocuparemos en otro lugar) reúnen una impresionante cantidad de información etnográfica y climatológica y de datos sobre la flora y fauna; los relatos fantásticos ya no figuran en este producto intelectual de fines de siglo xvII europeo. Excepcionalmente rico y detallado; y de una excepcional belleza, este Atlas de 1665, coloreado a mano como el de 1635 , le hace a América todo el honor que científicamente merecía.

La presencia de libros sobre América en bibliotecas particulares evidentemente no quiere decir que todos fueran leídos, pero lo mismo se puede decir acerca de los centenares de textos de los clásicos, y sus comentarios eruditos, que figuran en ellas. Como los atlas eran libros caros, parece razonable suponer que sus poseedores no los compraran exclusivamente por fines representativos (término de nuestros días, preocupación de todos los tiempos). Las sociedades mercantiles, las compañías que se dedicaban al comercio con los países de ultramar, tenían un interés vital por poder disponer de datos acerca de los países lejanos adonde iban sus barcos. Pensamos en la Compañía de las Indias Orientales (the Dutch East India Company), fundada en 1602, y en la de las Indias Occidentales, fundada en 1621. Pero también había buen número de comerciantes pudientes que estaban interesados en la misma información. Como en nuestros catálogos sólo figuran diez habitantes de Amsterdam (siete particulares y tres libreros), es muy probable que nuestros poseedores compraran sus atlas más bien por curiosidad intelectual o por motivos de índole científica.

12 Hemos consultado la edición con texto holandés. 
Los libros sobre América - historia, etnografía, libros de viajes, etc. - presentes en bibliotecas holandesas de los siglos Xvı y xvil ya nos hicieron dudar del tópico de que Erasmo y sus contemporáneos no se interesaban por el Mundus Novus. Los datos sobre los atlas en tales bibliotecas de intelectuales que ofrecemos aquí, han venido a reforzar esta duda. Evidentemente, los atlas que nos ocupan no venían dedicados exclusivamente al Nuevo Mundo, pero las Indias estaban muy presentes en ellos. Suponer que precisamente estas partes no fueran miradas ni leídas sería partir de un prejuicio muy curioso y difícil de explicar. Repetimos lo que hemos dicho en otro lugar: los editores - máxime, como en nuestro caso, los cartógrafos-editores- eran hombres de gran cultura, pero a la vez eran hombres de negocios que se veían obligados a tener en cuenta la situación del mercado so pena de hundirse. No editaban por motivos filantrópicos. Si, por lo tanto, América figura (además, tan extensamente) en determinados atlas, y de los más importantes, es que, por lo visto, los mapas y textos descriptivos podían contar con el interés del público lector.

En 66 de nuestros 139 catálogos hemos encontrado atlas en los que figuraba América; a veces, figura sólo uno; otras, más de uno y en algunos casos, excepcionales, hasta media docena y más (tratándose quizás de algún coleccionista o aficionado a la geografía). La cosmografía de Münster se lleva fácilmente la palma; se comprueba, efectivamente, que fue un libro popular, no obstante su impresionante grosor (1233 páginas), y se comprende por qué. En una época en que no abundaba la imagen impresa, el mero número y la diversidad de las estampas ofrecían un modo de esparcimiento excepcional a los espíritus curiosos. Añádase a esto el extenso texto y la información exótica que ofrecía sobre países y continentes lejanos, y no es difícil imaginarse su acogida entre el público culto.

Los atlas de Ortelius y Mercator, publicados respectivamente a partir de 1570 y 1606 , ocupan el segundo lugar ${ }^{13}$. De los atlas de Blaeu, de 1635 y 1665 y ediciones posteriores, sólo figuran pocos ejemplares. Lo mismo cabe observar acerca del de Janssonius (Juan Janszoon Brouwer, 1588-1644), otro cartógrafo de los Países Bajos Septentrionales, yerno de Hondius, fundador de una

13 Sólo hemos contado los casos en que la descripción bibliográfica no de. jaba lugar a dudas de que, efectivamente, se trataba de un atlas en que vient representada América. En teoría, es posible, pues, que entre las otras entra. das ("Atlas Mercatoris" y "Atlas Ortelij", por ejemplo) se encuentren ejem. plares en que figuraba América. 
casa editorial muy importante, con sucursales en Lyon, Ginebra y Estocolmo; él continuó las reediciones del atlas de Mercator de 1595 que había iniciado su suegro. Por ello sería más correcto contar el número de atlas de Janssonius en el apartado de los de Mercator.

Un libro impresionante, lo menos tan costoso como los grandes atlas que hemos mencionado, fue el atlas urbano de Georg Braun y el grabador Frans Hogenberg, titulado Civitates Orbis Terrarum, del que aparecieron cinco volúmenes en folio entre 1572 y 1598 y un sexto tomo en 1617 . Se trata de una magnífica colección de grabados que representan ciudades del mundo hasta entonces conocido, entre los que se encuentran uno de México y otro de Cuzco (que por otra parte no procedían de los buriles de Hogenberg, sino que ya habían sido publicados anteriormente) $)^{14}$.

\begin{tabular}{lr} 
Münster, 1544 & 47 \\
Mercator, 1538, 1569 & 35 \\
Ortelius, 1570 & 31 \\
Hondius, 1606 & 5 \\
Blaeu, 1635, 1665 & 6 \\
Janssonius, 1658 & 6 \\
Braun-Hogenberg & $\underline{7}$ \\
\multicolumn{1}{r}{ Total: } & 137 \\
\hline
\end{tabular}

Los poseedores de atlas se encuentran sobre todo entre los pastores protestantes, los catedráticos y los funcionarios (se trata casi siempre de altos funcionarios, que trabajan en la Gorte de Holanda en La Haya). Hay también algunos médicos, poquísimos hombres de negocios y algunos directores de Escuelas Latinas, a los que se podría añadir un grupo compuesto por anónimos o gente cuya profesión no figura en el catálogo de venta de sus libros.

14 Hemos consultado la edición facsímil, con introducción de R. A. Skelton, hecha por Theatrum Orbis Terrarum, Amsterdam, 1965. La estampa de Cuzco ya se había editado anteriormente en AnToine du Pinet, Plantz, pourtraitz et descriptions de plusieurs villes et forteresses (Lyon, 1564), a partir de una estampa que figuraba en el tercer volumen de las Navegationi de Ramusio, de 1556. La de Cuzco, procedente originalmente de un plano publicado en el Isolario (1528) de B. Bordone, ya aparecía también en el libro de Pinet. 
PROFESIONES DE LOS QUE POSEIAN. ATLAS 1600-1700

\begin{tabular}{|c|}
\hline Pastor \\
\hline Catedrático \\
\hline Funcionario \\
\hline Médico \\
\hline Negociante \\
\hline Director de colegio \\
\hline Otros \\
\hline
\end{tabular}

El contenido de todas estas bibliotecas de las que hemos visto los catálogos de venta, además de algunos de libreros, confirman - ¿cómo no iba a ser así? - lo que sabíamos: que la Europa del Renacimiento y decenios posteriores se interesaba apasionadamente por la Antigüedad clásica. Dado el gran número de pastores protestantes que se encuentran entre los poseedores y teniendo en cuenta el clima general que reinaba en Europa desde la Refor$\mathrm{ma}$, no es de extrañar tampoco que figure un número tan considerable de ediciones de textos religiosos y estudios teológicos.

Lo que cada día nos parece más difícil de sostener es la tesis de que Europa no se interesaba en absoluto por el Orbis Novus. Un despojo sistemático, a escala europea, de inventarios de bibliotecas de intelectuales hechos durante la vida de éstos, y sobre todo de los inventarios hechos a la muerte de sus poseedores, así como de catálogos de venta de libros, podría aportar más datos para dilucidar esta cuestión.

JAN LECHNER 